\title{
Inhibitory Effects of Cordycepin on Platelet Activation via Regulation of Cyclic Adenosine Monophosphate-downstream Pathway
}

\author{
Dong-Ha Lee ${ }^{\dagger}$ \\ Department of Biomedical Laboratory Science, Korea Nazarene University, Cheonan 31172, Korea
}

\begin{abstract}
Platelet activation is essential at the sites of vascular injury, which leads to hemostasis through adhesion, aggregation, and secretion process. However, potent and continuous platelet activation may be an important reason of circulatory disorders. Therefore, proper regulation of platelet activation may be an effective treatment for vascular diseases. In this research, inhibitory effects of cordycepin (3'-deoxyadenosine) on platelet activation were determined. As the results, cordycepin increased cAMP and cGMP, which are intracellular $\mathrm{Ca}^{2+}$-antagonists. In addition, cordycepin reduced collagenelevated $\left[\mathrm{Ca}^{2+}\right]_{\mathrm{i}}$ mobilization, which was increased by a cAMP-dependent protein kinase (PKA) inhibitor (Rp-8-BrcAMPS), but not a cGMP-protein kinase (PKG) inhibitor (Rp-8-Br-cGMPS). Furthermore, cordycepin increased IP ${ }_{3} \mathrm{RI}$ $\left(\mathrm{Ser}^{1756}\right)$ phosphorylation, indicating inhibition of $\mathrm{IP}_{3}$-mediated $\mathrm{Ca}^{2+}$ release from internal store via the $\mathrm{IP}_{3} \mathrm{RI}$, which was strongly inhibited by Rp-8-Br-cAMPS, but was not so much inhibited by Rp-8-Br-cGMPS. These results suggest that the reduction of $\left[\mathrm{Ca}^{2+}\right]_{i}$ mobilization is caused by the cAMP/A-kinase-dependent $\mathrm{IP}_{3} \mathrm{RI}\left(\mathrm{Ser}^{1756}\right)$ phosphorylation. In addition, cordycepin increased the phosphorylation of VASP $\left(\mathrm{Ser}^{157}\right)$ known as PKA substrate, but not VASP $\left(\mathrm{Ser}^{239}\right)$ known as PKG substrate. Cordycepin-induced VASP $\left(\mathrm{Ser}^{157}\right.$ ) phosphorylation was inhibited by Rp-8-Br-cAMPS, but was not inhibited by Rp- 8 -Br-cGMPS, and cordycepin inhibited collagen-induced fibrinogen binding to $\alpha \mathrm{IIb} / \beta_{3}$, which was increased by Rp-8-Br-cAMPS, but was not inhibited by Rp-8-Br-cGMPS. These results suggest that the inhibition of $\alpha \mathrm{IIb} / \beta_{3}$ activation is caused by the cAMP/A-kinase-dependent VASP $\left(\mathrm{Ser}^{157}\right)$ phosphorylation. In conclusion, these results demonstrate that inhibitory effects of cordycepin on platelet activation were due to inhibition of $\left[\mathrm{Ca}^{2+}\right]_{\mathrm{i}}$ mobilization through cAMP-dependent IP ${ }_{3} \mathrm{RI}\left(\mathrm{Ser}^{1756}\right)$ phosphorylation and suppression of $\alpha \mathrm{IIb} / \beta_{3}$ activation through cAMP-dependent VASP $\left(\operatorname{Ser}^{157}\right)$ phosphorylation. These results strongly indicated that cordycepin might have therapeutic or preventive potential for platelet activation-mediated disorders including thrombosis, atherosclerosis, myocardial infarction, or cardiovascular disease.
\end{abstract}

Key Words: Cordycepin, $\mathrm{Ca}^{2+}$ mobilization, cAMP, Inositol trisphosphate receptor, VASP, Fibrinogen binding

\section{INTRODUCTION}

Platelets are activated by several molecules (i.e., collagen, ADP and thrombin) at the sites of vascular injury, which is essential hemostatic process. However, it can also lead to circulatory disorders, including thrombosis, atherosclerosis, or myocardial infarction (Schwartz et al., 1990). Therefore, inhibition of platelet activation might be an effective approach to prevent vascular diseases. When collagen is released from the vascular endothelial cell in vascular injury, it binds to the receptor glycoprotein VI (GP VI), and then

*Received: April 25, 2017 / Revised: August 11, 2017 / Accepted: August 20, 2017

${ }^{\dagger}$ Corresponding author: Dong-Ha Lee. Department of Biomedical Laboratory Science, Wolbong-Ro 48, Seobuk-gu, Cheonan 31172 , Korea. Tel: +82-41-570-1680, Fax: +82-41-570-4258, e-mail: 1dh@kornu.ac.kr

(C) The Korean Society for Biomedical Laboratory Sciences. All rights reserved.

(C) This is an Open Access article distributed under the terms of the Creative Commons Attribution Non-Commercial License (http://creativecommons.org/licenses/by-nc/3.0/) which permits unrestricted non-commercial use, distribution, and reproduction in any medium, provided the original work is properly cited. 
platelets activate by tyrosine kinase-dependent mechanisms, which is related to phospholipase C- $\gamma_{2}\left(\mathrm{PLC}-\gamma_{2}\right)$ phosphorylation (Wonerow et al., 2002). The phosphorylated PLC- $\gamma_{2}$ produces diacylglycerol (DG) and inositol 1, 4, 5trisphosphate $\left(\mathrm{IP}_{3}\right)$ hydrolyzing phosphatidylinositol 4, 5bisphosphate $\left(\mathrm{PIP}_{2}\right) . \mathrm{IP}_{3}$ mobilizes cytosol free $\mathrm{Ca}^{2+}\left(\left[\mathrm{Ca}^{2+}\right]_{\mathrm{i}}\right)$ from dense tubular system through $\mathrm{IP}_{3}$ receptor type $\mathrm{I}\left(\mathrm{IP}_{3} \mathrm{RI}\right)$, which works as calcium ion channel (Quinton et al., 1992). The increased $\left[\mathrm{Ca}^{2+}\right]_{\mathrm{i}}$ phosphorylates myosin light chain (MLC) via activation of $\mathrm{Ca}^{2+} /$ calmodulin-dependent protein kinase, which induces platelet aggregation and granule secretion (Nishikawa et al., 1980; Kaibuchi et al., 1982). On the other hand, cyclic adenosine monophosphate (cAMP) or cyclic guanosine monophosphate (cGMP) has antiplatelet effects by decreasing the $\left[\mathrm{Ca}^{2+}\right]_{\mathrm{i}}$ mobilization (Menshikov et al., 1993; Schwarz et al., 2001). The cAMP or cGMP activate cAMP- or cGMP-dependent protein kinases (PKA or $\mathrm{PKG})$, which phosphorylate substrate proteins, $\mathrm{IP}_{3} \mathrm{RI}$ and vasodilator-stimulated phosphoprotein (VASP) (Halbrügge et al., 1990; Butt et al., 1994). IP $\mathrm{IPI}_{3}\left(\mathrm{Ser}^{1756}\right)$ phosphorylation results in inhibition of $\left[\mathrm{Ca}^{2+}\right]_{\mathrm{i}}$ mobilization (Quinton et al., 1992; Schwarz et al., 2001), and VASP (Ser ${ }^{157}$ and $\operatorname{Ser}^{239}$ ) phosphorylation leads to inhibition of fibrinogen binding to glycoprotein IIb/IIIa $\left(\alpha \mathrm{IIb} / \beta_{3}\right)$, so that they consequentially inhibit platelet activation (Laurent et al., 1999; Sudo et al., 2003). Therefore, regulation of these cascades is good factor for evaluating antiplatelet effects of any compound or substance.

A species of Cordyceps known as ingredient of Chinese traditional medicine is prescribed for inflammatory and cancer diseases, and its major component is cordycepin (3'deoxyadenosine). In previous report, cordycepin (3'-deoxyadenosine, Fig. 1) from Cordyceps militaris has antiplatelet effects in cAMP- and cGMP-dependent manner, which is involved in down-regulation of $\left[\mathrm{Ca}^{2+}\right]_{\mathrm{i}}$ and $\mathrm{TXA}_{2}$ (Cho et al., 2007). However, its pathway remains uncertain and it is unknown how cordycepin regulates cAMP- or cGMP downstream pathway (i.e. phosphorylation of $\mathrm{IP}_{3} \mathrm{RI}$ and VASP). In this study, we investigated how cordycepin regulates cAMPor cGMP downstream pathway to inhibit platelets activation. These provide novel information and possibility of cordycepin as an antiplatelet drug.

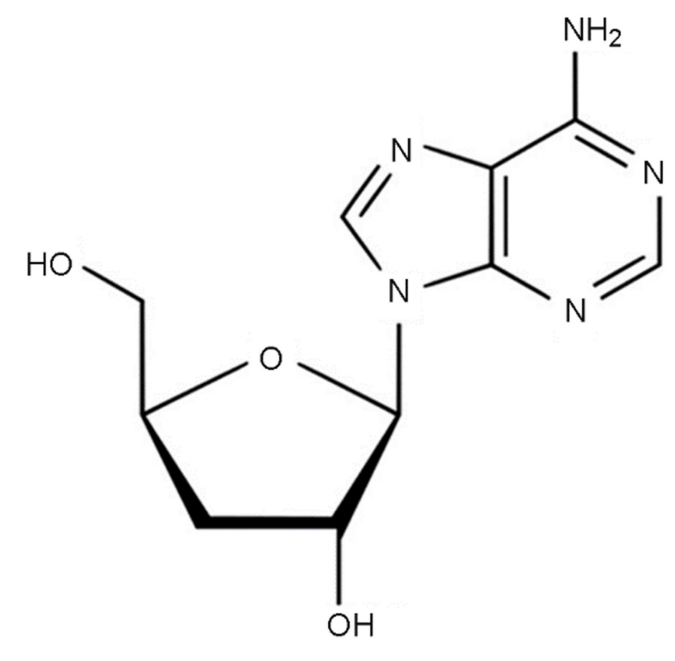

Cordycepin (3'-deoxyadenosine)

Fig. 1. Chemical structure of cordycepin (3'-deoxyadenosine).

\section{MATERIALS AND METHODS}

\section{Materials}

Cordycepin, Fura 2-AM, and other reagents were purchased from Sigma Chemical Corporation (St. Louis, MO., USA). Collagen was purchased from Chrono-Log Co. (Havertown, PA., USA). Lysis buffer and Antibodies for western blotting were purchased from Cell Signaling Co. (Beverly, MA., USA). Polyvinylidene difluoride (PVDF) membrane and enhanced chemiluminesence (ECL) solution were obtained from GE Healthcare (Chalfont St., Giles, Buckinghamshire, UK), and Fibrinogen Alexa Fluor 488 conjugate was purchased from Invitrogen Molecular Probes (Eugene, OR., USA).

\section{Preparation of washed platelets}

Human platelet-rich plasma (PRP) treated by ACD anticoagulant $(2.2 \%$ sodium citrate, $0.8 \%$ citric acid, $2.45 \%$ dextrose) was offered from Korean Red-Cross Blood Center (Changwon, Korea). PRP was centrifuged at 1,300 $\mathrm{g}$ for 10 min to obtain platelets removing a little red blood cell, and the platelets were washed twice with washing buffer (138 $\mathrm{mM} \mathrm{NaCl}, 12 \mathrm{mM} \mathrm{NaHCO} 3,5.5 \mathrm{mM}$ glucose, $2.7 \mathrm{mM} \mathrm{KCl}$, $1 \mathrm{mM}$ EDTA, and $0.36 \mathrm{mM} \mathrm{NaH}_{2} \mathrm{PO}_{4}, \mathrm{pH}$ 6.5). The washed 
platelets were suspended in suspending buffer $(138 \mathrm{mM}$ $\mathrm{NaCl}, 12 \mathrm{mM} \mathrm{NaHCO} 3,5.5 \mathrm{mM}$ glucose, $2.7 \mathrm{mM} \mathrm{KCl}$, $0.49 \mathrm{mM} \mathrm{MgCl}_{2}, 0.36 \mathrm{mM} \mathrm{NaH}_{2} \mathrm{PO}_{4}$, and $0.25 \%$ gelatin, $\mathrm{pH} 6.9$ ) to $5 \times 10^{8} / \mathrm{mL}$ of final concentration. All this procedures were carried out avoiding platelet aggregation at $25^{\circ} \mathrm{C}$.

\section{Measurement of cAMP and cGMP level}

Washed platelets $\left(10^{8} / \mathrm{mL}\right)$ were pre-incubated with the compound in $2 \mathrm{mM} \mathrm{CaCl}_{2}$ at $37^{\circ} \mathrm{C}$ for $3 \mathrm{~min}$, and stimulated by $10 \mu \mathrm{g} / \mathrm{mL}$ collagen at $37^{\circ} \mathrm{C}$ for $5 \mathrm{~min}$. The reaction was terminated with $80 \%$ ice-cold ethanol, and cAMP and cGMP were determined by cAMP and cGMP EIA kits using synergy HT multi-model microplate reader.

\section{Measurement of cytosolic-free $\mathrm{Ca}^{2+}$ mobilization}

Fura 2-loaded platelets were prepared by incubating PRP in the presence of $5 \mu \mathrm{M}$ Fura $2-\mathrm{AM}$ at $37^{\circ} \mathrm{C}$ for $60 \mathrm{~min}$, and were pre-incubated with the compound in $2 \mathrm{mM} \mathrm{CaCl}_{2}$ at $37^{\circ} \mathrm{C}$ for $3 \mathrm{~min}$, and stimulated with $10 \mu \mathrm{g} / \mathrm{mL}$ collagen at $37^{\circ} \mathrm{C}$ for $5 \mathrm{~min}$ to determine cytosolic-free $\mathrm{Ca}^{2+}\left(\left[\mathrm{Ca}^{2+}\right]_{\mathrm{i}}\right)$ mobilization. Fura 2 fluorescence was determined by a spectrofluorometer (SFM 25; Bio-Teck Instrument, Italy) in the excitation wavelength changing each 0.5 second from 340 to $380 \mathrm{~nm}$ and the emission wavelength at $510 \mathrm{~nm}$. The $\left[\mathrm{Ca}^{2+}\right]_{\mathrm{i}}$ were calculated by the method of Schaeffer (Schaeffer et al., 1989).

\section{Western blot for analysis of $\mathrm{IP}_{3} \mathrm{RI}$-, VASP-phospho- rylations}

Washed platelets $\left(10^{8} / \mathrm{mL}\right)$ were pre-incubated with the compound in $2 \mathrm{mM} \mathrm{CaCl}$ for $3 \mathrm{~min}$, and stimulated with $10 \mu \mathrm{g} / \mathrm{mL}$ collagen at $37^{\circ} \mathrm{C}$ for $5 \mathrm{~min}$. The reactions were terminated with equal volume $(250 \mu \mathrm{L})$ of lysis buffer (Cayman Chemical Co., MI., USA). Platelet lysates containing $15 \mu \mathrm{g}$ protein were used for analysis. The effects of cordycepin on $\mathrm{IP}_{3} \mathrm{RI}$-, VASP-phosphorylation were analyzed by western blotting. 6 8\% SDS-PAGE were used for electrophoresis, and PVDF membrane was used for gel transfer. The membranes were visualized with ECL, which was analyzed by the Quantity One, Ver. 4.5 (Hercules, CA., USA).

\section{Measurement of fibrinogen binding to platelets}

Washed platelets $\left(10^{8} / \mathrm{mL}\right)$ were pre-incubated with the compound in $2 \mathrm{mM} \mathrm{CaCl}_{2}$ for $3 \mathrm{~min}$, and stimulated with $10 \mu \mathrm{g} / \mathrm{mL}$ collagen in the presence of $30 \mu \mathrm{g} / \mathrm{mL}$ Alexa Flour 488-human fibrinogen at room temperature for $5 \mathrm{~min}$. The reaction was terminated with $0.5 \%$ paraformaldehyde in phosphate-buffered saline, which were placed in the dark. Alexa Fluor 488-fibrinogen binding to platelets was measured using flow cytometry (San Jose, CA., USA) and the data are analyzed by cellQuest software.

\section{Statistical analyses}

These data were expressed as the mean \pm SEM accompanied with the number of observations. These data were assessed through analysis of variance (ANOVA). If the analysis indicated significant differences among the control group means, the each group was compared through the Newman-Keuls method. $P<0.05$ was considered to have statistically significant mean.

\section{RESULTS \& DISCUSSION}

We examined whether cordycepin was concerned with elevation of cAMP or cGMP in collagen-stimulated platelet activation. As the result, collagen reduced intracellular cAMP production to $46.2 \%$ as compared with basal level (Table 1 , Fig. 2A). However, when platelets were incubated in the presence of both cordycepin and collagen, the level of cAMP was increased to $8.3 \pm 0.7 \mathrm{pmoL} / 10^{9}$ platelets (Table 1 , Fig. 2A), which increased collagen-decreased cAMP level to $196.4 \%$ (Table 1, Fig. 2A). On the contrary, collagen reduced intracellular cGMP production to $25.0 \%$ as compared with basal level (Table 1, Fig. 2B). However, when platelets were incubated in the presence of cordycepin and collagen, the cGMP level was increased to $46.7 \%$ as compared with the result $\left(3.0 \pm 0.4 \mathrm{pmoL} / 10^{9}\right.$ platelets) by collagen only (Table 1, Fig. 2B). The intracellular cAMP and cGMP levels are regulated by balance between cyclic nucleotide-producing enzymes such as adenylate/guanylate cyclase, and hydrolyzing enzymes such as cAMP/cGMP phosphodiesterases (PDEs). It is known that platelets have $\mathrm{PDE}_{2}, \mathrm{PDE}_{3}$, and 
Table 1. Changes of cAMP and cGMP

\begin{tabular}{|c|c|c|c|c|c|c|}
\hline & \multicolumn{2}{|c|}{ cAMP } & \multicolumn{2}{|c|}{ cGMP } & \multicolumn{2}{|c|}{ cAMP/cGMP } \\
\hline & $\begin{array}{l}\mathrm{pmoL} / 10^{9} \\
\text { platelets }\end{array}$ & Change (\%) & $\begin{array}{c}\mathrm{pmoL} / 10^{9} \\
\text { platelets }\end{array}$ & Change (\%) & Ratio & $\begin{array}{c}\text { Change } \\
(\%)\end{array}$ \\
\hline Base & $5.2 \pm 0.4$ & - & $4.0 \pm 0.3$ & - & 1.3 & - \\
\hline Collagen $(10 \mu \mathrm{g} / \mathrm{mL})$ & $2.8 \pm 0.5^{\mathrm{a}}$ & $-46.2^{1)}$ & $3.0 \pm 0.4^{\mathrm{a}}$ & $-25.0^{2)}$ & 0.9 & $-30.7^{3)}$ \\
\hline $\begin{array}{l}\text { Collagen }(10 \mu \mathrm{g} / \mathrm{mL})+ \\
\text { cordycepin }(500 \mu \mathrm{M})\end{array}$ & $8.3 \pm 0.7^{* *}$ & $+196.4^{4)}$ & $4.4 \pm 0.6^{*}$ & $+46.7^{5)}$ & 1.9 & $+111.1^{6}$ \\
\hline
\end{tabular}

Data are from Fig. 2A, B. 1) to 3) Changes to base; 4) to 6) Changes to collagen

1) and 2$)$ of inhibition $(\%)=($ Base - Collagen $) /$ Base $\times 100$

4) and 5) of inhibition $(\%)=[($ Collagen + cordycepin $)-$ Collagen $] /$ Collagen $\times 100$

3) ratio decrease $(\%)=($ Base - Collagen $) /$ Base $\times 100$

6) ratio increase $(\%)=[($ Collagen + cordycepin $)-$ Collagen $] /$ Collagen $\times 100$

These data were expressed as the mean $\pm \operatorname{SEM}(\mathrm{n}=4)$. ${ }^{\mathrm{a}} P<0.05$ compared with base, ${ }^{*} P<0.05,{ }^{* *} P<0.001$ compared with the collagenstimulated platelets.
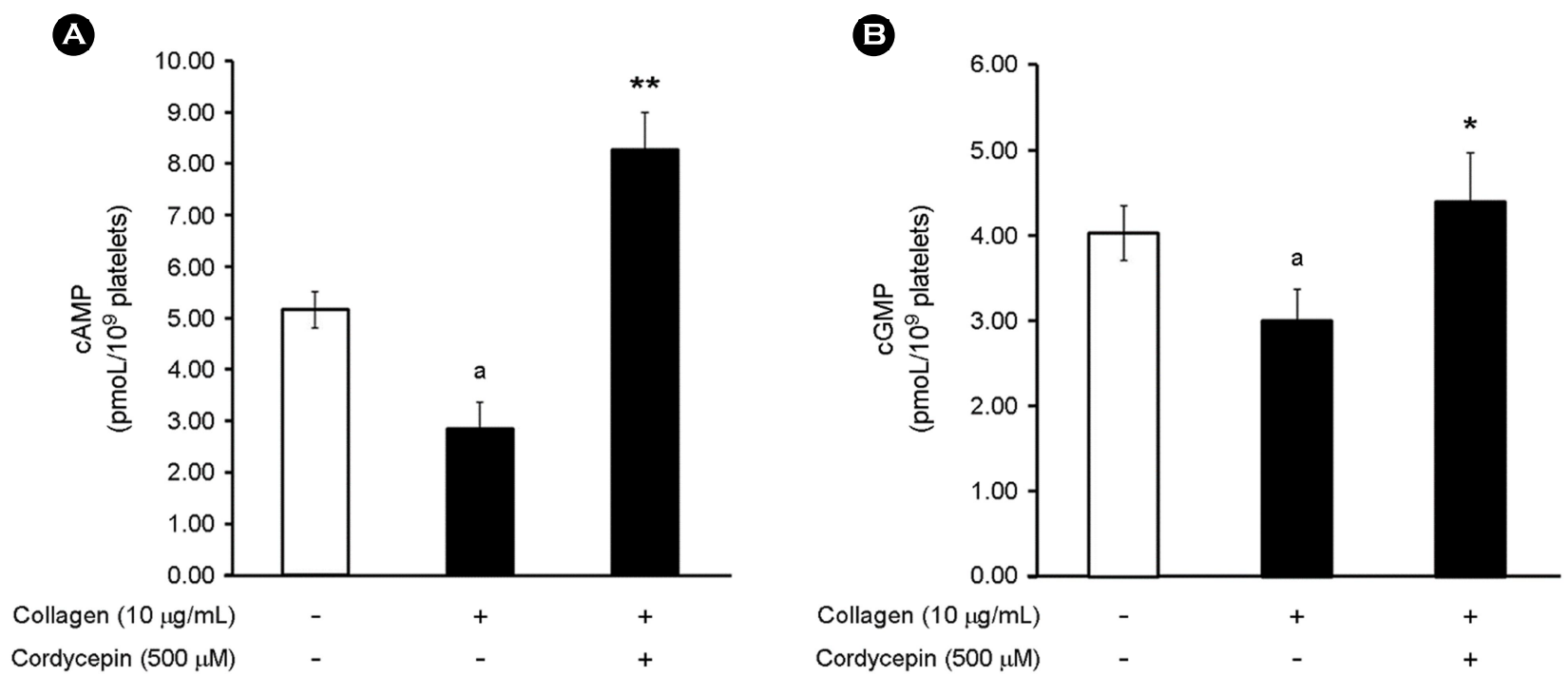

Fig. 2. Effect of cordycepin on cAMP and cGMP production. (A) Effect of cordycepin on cAMP production in collagen-induced platelets. (B) Effect of cordycepin on cGMP production in collagen-induced platelets. The level of cAMP and cGMP was examined as described in "Methods". These data were expressed as the mean \pm SEM $(n=4)$. These data were expressed as the mean \pm S.E.M. $(n=4)$. ${ }^{a} P<0.05$ compared with the non-stimulated platelets, ${ }^{*} P<0.05,{ }^{* *} P<0.001$ compared with the collagen-stimulated platelets.

$\mathrm{PDE}_{5}$ (Schwarz et al., 2001; Walter et al., 2009). PDE 2 hydrolyzes both cAMP and cGMP as cGMP-stimulated PDE, $\mathrm{PDE}_{3}$ hydrolyzes cAMP rather than cGMP as cGMPinhibited PDE, and $\mathrm{PDE}_{5}$ hydrolyzes cGMP only as cGMPbinding-cGMP specific PDE. Because cordycepin increased both cAMP and cGMP in collagen-induced platelet aggregation, although it is thought that cordycepin might involve inhibition of $\mathrm{PDE}_{2}$ to increase both cAMP and cGMP, we cannot exclude that cordycepin might involve activation of adenylate cyclase to produce cAMP from ATP, because cordycepin-elevated cAMP level was decreased by adenylate cyclase inhibitor SQ22536 (Cho et al., 2007). Nieswandt group provided an evidence for cross-talk between collagen receptor GPVI and $\mathrm{G}_{\mathrm{i}}$-coupled receptor during collageninduced platelet aggregation (Nieswandt et al., 2001). If so, there is a possibility that collagen-reduced cAMP was medi- 

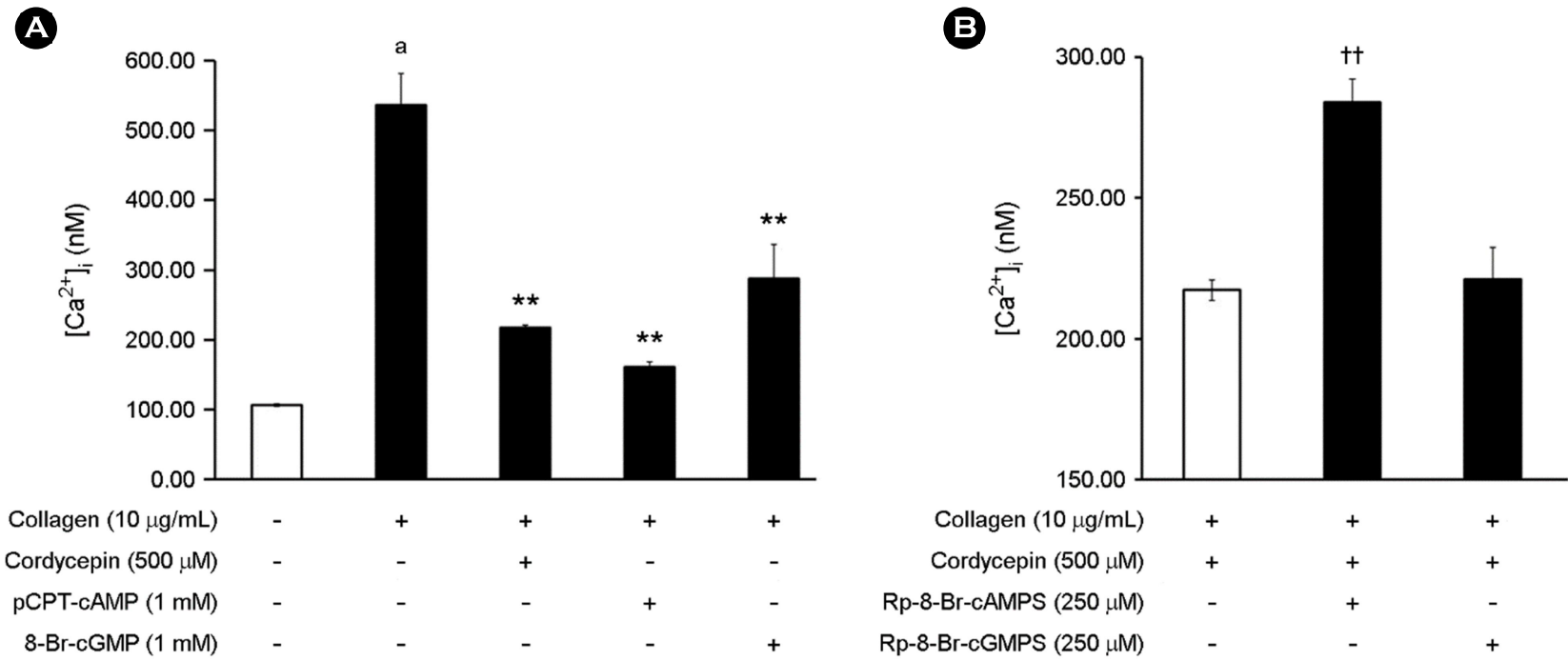

Fig. 3. Effects of cordycepin on $\left[\mathrm{Ca}^{2+}\right]_{\mathrm{i}}$ mobilization. (A) Effects of cordycepin on collagen-stimulated $\left[\mathrm{Ca}^{2+}\right]_{\mathrm{i}}$ mobilization. (B) Effects of cordycepin on collagen-stimulated $\left[\mathrm{Ca}^{2+}\right]_{\mathrm{i}}$ mobilization in the presence of Rp-8-Br-cAMPS (PKA inhibitor), or Rp-8-Br-cGMPS (PKG inhibitor). The level of $\left[\mathrm{Ca}^{2+}\right]_{\mathrm{i}}$ was examined as described in "Methods". These data were expressed as the mean \pm SEM $(\mathrm{n}=4)$, and ${ }^{\mathrm{a}} P<0.05$ compared with the non-stimulated platelets, ${ }^{* *} P<0.001$ versus the collagen-stimulated platelets, ${ }^{\dagger \dagger} P<0.001$ compared with the collagenstimulated platelets in the presence of $500 \mu \mathrm{M}$ cordycepin.

ated via $\mathrm{G}_{\mathrm{i}}$-coupled receptor, and by contrast, the elevation of cAMP level achieved by cordycepin was induced by $\mathrm{G}_{\mathrm{s}}$-coupled receptor through adenylate cyclase activation. This is supported from report (Johnston-Cox et al., 2011) adenosine and the analogues increase cAMP level via adenosine receptor $\mathrm{A}_{2} \mathrm{~A}$, which are coupled to Gs-coupled receptor. Cordycepin is an analogue of adenosine as 3'deoxyadenosine. cGMP is known to be produced via the activation of guanylate cyclase in the presence or absence of nitric oxide (NO) synthesized in platelets (Pasqui et al., 1991). Because cordycepin did not produce NO in platelets (Cho et al., 2007), the elevation of cGMP achieved by cordycepin is independent on $\mathrm{NO}$ /guanylate cyclase pathway.

In addition, collagen-elevated $\left[\mathrm{Ca}^{2+}\right]_{i}$ was potently decreased by $500 \mu \mathrm{M}$ of cordycepin, and PKA activator pCPTcAMP or PKG activator 8-Br-cGMP reduced collagenelevated $\left[\mathrm{Ca}^{2+}\right]_{\mathrm{i}}$ (Fig. 3A). Because $\left[\mathrm{Ca}^{2+}\right]_{\mathrm{i}}$ level could be reduced through $\mathrm{cAMP} / \mathrm{PKA}$ or cGMP/PKG downstream pathway, next, we investigated whether cordycepin is concerned with cAMP/PKA or cGMP/PKG downstream pathway to decrease $\left[\mathrm{Ca}^{2+}\right]_{\mathrm{i}}$ level. As shown in Fig. $3 \mathrm{~B},\left[\mathrm{Ca}^{2+}\right]_{\mathrm{i}}$ level in the presence of both collagen and cordycepin was
$217.2 \pm 3.6 \mathrm{nM}$, which was significantly elevated by PKA inhibitor Rp-8-Br-cAMPS to $283.9 \pm 8.2 \mathrm{nM}$ (Fig. 3B). On the other hand, the $\left[\mathrm{Ca}^{2+}\right]_{i}$ level in the presence of both collagen and cordycepin was not elevated by PKG inhibitor Rp-8-Br-cGMPS (Fig. 3B). Because $\left[\mathrm{Ca}^{2+}\right]_{\mathrm{i}}$ reduction could be resulted from cAMP/PKA-, or cGMP/PKG-phosphorylated $\mathrm{IP}_{3} \mathrm{RI}\left(\mathrm{Ser}^{1756}\right)$, next we checked whether cordycepin induces $\mathrm{IP}_{3} \mathrm{RI}\left(\mathrm{Ser}^{1756}\right)$ phosphorylation. As shown in Fig. 4 lane 3 , and the ratio of phospho-IP ${ }_{3} \mathrm{RI}\left(\mathrm{Ser}^{1756}\right)\left[\mathrm{p}-\mathrm{IP}{ }_{3} \mathrm{RI}\right]$ to $\beta$-actin strongly increased in the presence of collagen and cordycepin. However, Rp-8-Br-cAMPS potently decreased the ratio of $\mathrm{p}-\mathrm{IP}{ }_{3} \mathrm{RI}$ increased by both collagen and cordycepin (Fig. 4 lane 4), but not Rp-8-Br-cGMPS (Fig. 4 lane 5). In addition, the ratio of $\mathrm{p}-\mathrm{IP}_{3} \mathrm{RI}$ were increased in the presence of both collagen and $1 \mathrm{mM} \mathrm{pCPT-cAMP}$ as PKA activator, or $1 \mathrm{mM}$ 8-Br-cGMP as PKG activator (Fig. 4 lane 6 and 7). Accordingly, cAMP/PKA-dependent $\mathrm{IP}_{3} \mathrm{RI}$ $\left(\mathrm{Ser}^{1756}\right)$ phosphorylation exclusively contributed to the inhibition of $\left[\mathrm{Ca}^{2+}\right]_{i}$ mobilization by cordycepin in collagenactivated platelets.

Another downstream pathway of cAMP/PKA or cGMP/ PKG is VASP phosphorylation, which is concerned with 


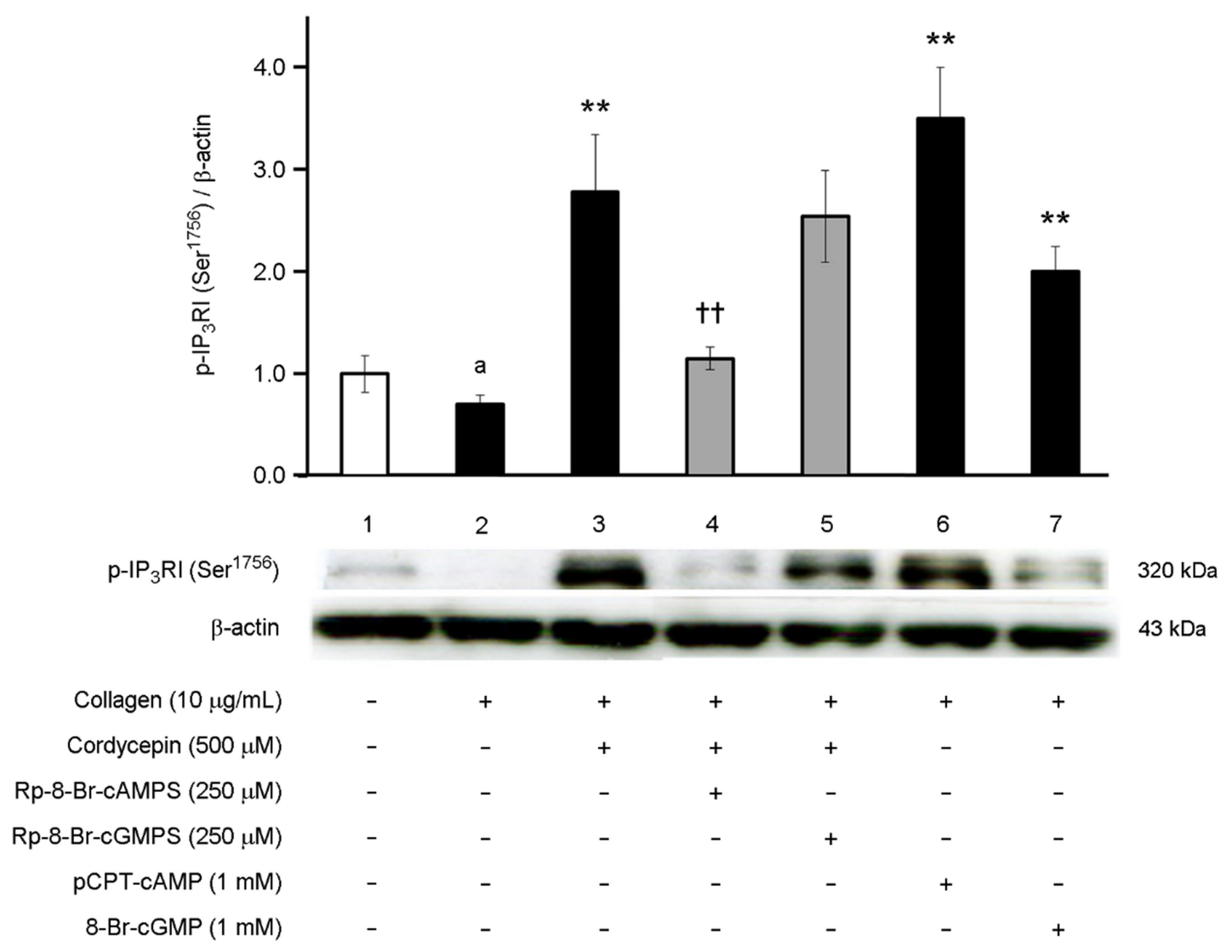

Fig. 4. Effects of cordycepin on inositol 1,4,5-trisphosphate receptor type $\mathrm{I}\left(\mathrm{IP}_{3} \mathrm{RI}\right)\left(\mathrm{Ser}^{1756}\right)$ phosphorylation. The phosphorylation was determined as described in "Materials and Methods". These data were expressed as the mean \pm SEM $(\mathrm{n}=4)$, and ${ }^{\mathrm{a}} P<0.05$ compared with the non-stimulated platelets, ${ }^{* *} P<0.001$ compared with the collagen-stimulated platelets, ${ }^{\dagger} P<0.001$ compared with the collagen-stimulated platelets in the presence of $500 \mu \mathrm{M}$ cordycepin.

$\alpha \mathrm{IIb} / \beta_{3}$ inactivation inhibiting platelet aggregation. The cAMP/PKA pathway phosphorylates Ser $^{157}$ of VASP, whereas the cGMP/PKG pathway phosphorylates $\operatorname{Ser}^{239}$ of VASP (Horstrup et al., 1994; Smolenski et al., 1998). Therefore, examination of VASP phosphorylation is a useful indicator for monitoring cAMP/PKA- or cGMP/PKG-pathway. As the results, collagen increased weakly phosphorylation of $\mathrm{Ser}^{157}$ at $50 \mathrm{kDa}$ of VASP [p-VASP $\left(\mathrm{Ser}^{157}\right)$ ] (Fig. 5 lane 2). It is known that thrombin or collagen is concerned with a feedback inhibition by increasing p-VASP $\left(\mathrm{Ser}^{157}\right.$ ) (Gambaryan et al., 2010). A PKA activator pCPT-cAMP increased p$\operatorname{VASP}\left(\mathrm{Ser}^{157}\right)$ (Fig. 5 lane 6), which means that cAMP/PKA pathway results in phosphorylation of VASP $\left(\mathrm{Ser}^{157}\right)$. In addition, cordycepin increased the ratio of p-VASP $\left(\mathrm{Ser}^{157}\right)$ in collagen-induced platelet activation (Fig. 5 lane 3), and
Rp-8-Br-cAMPS decreased cordycepin-elevated p-VASP $\left(\mathrm{Ser}^{157}\right.$ ) (Fig. 5 lane 4). On the other hand, even if PKG activator 8-Br-cGMP increased p-VASP $\left(\mathrm{Ser}^{239}\right)$ indicating the activation of PKG via cGMP (Fig. 5 lane 7), the p-VASP $\left(\mathrm{Ser}^{239}\right)$ was not observed in the presence of both collagen and cordycepin (Fig. 5 lane 3). In addition, p-VASP $\left(\mathrm{Ser}^{239}\right)$ was not changed by Rp-8-Br-cGMPS in the presence of cordycepin (Fig. 5 lane 5). Accordingly, the elevation of pVASP $\left(\mathrm{Ser}^{157}\right)$ by cordycepin was obviously resulted from cAMP/PKA pathway in collagen-activated platelets. As the result, cordycepin phosphorylated VASP $\left(\mathrm{Ser}^{157}\right)$, but VASP $\left(\mathrm{Ser}^{239}\right)$ is not. These can be explained by the previous report that a small elevation in cAMP is enough to activate most PKA potently, whereas even several fold elevation of the cGMP level may stimulate only a small fraction of total 


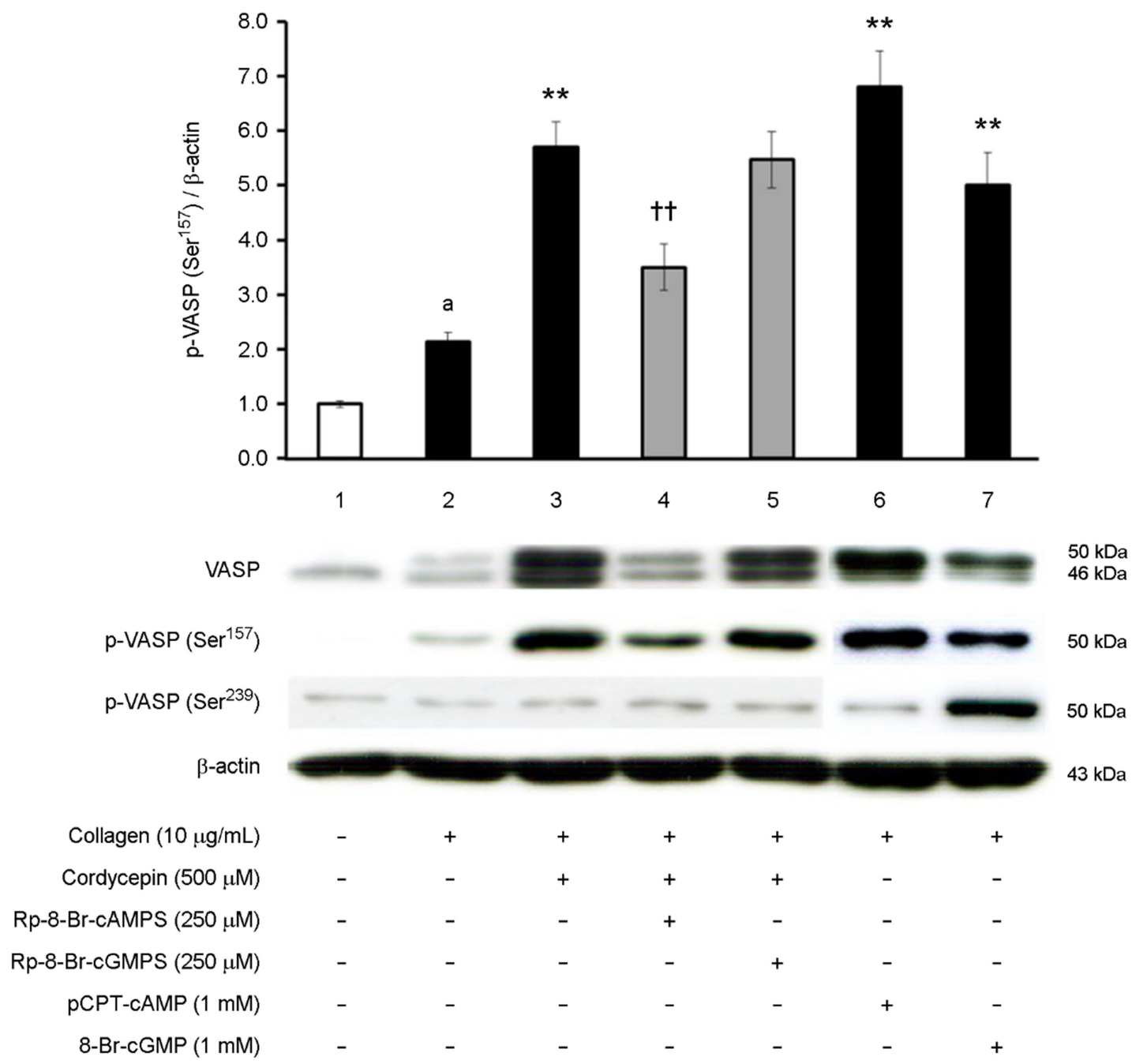

Fig. 5. Effects of cordycepin on VASP phosphorylation. The phosphorylation was determined as described in "Methods". These data were expressed as the mean \pm SEM $(\mathrm{n}=4)$, and ${ }^{\mathrm{a}} P<0.05$ compared with the non-stimulated platelets, ${ }^{* *} P<0.001$ compared with the collagenstimulated platelets, ${ }^{\dagger} P<0.001$ compared with the collagen-stimulated platelets in the presence of $500 \mu \mathrm{M}$ cordycepin.

PKG (Eigenthaler et al., 1992). This report reflects that a little cAMP level is enough to phosphorylate $\operatorname{VASP}\left(\operatorname{Ser}^{157}\right)$, but more cGMP level is required to phosphorylate VASP $\left(\mathrm{Ser}^{239}\right)$. In this study, cordycepin increased cAMP level 1.9 fold more than cGMP level (Table 1). Accordingly, it is thought that cordycepin-elevated cGMP level is not enough to phosphorylate VASP $\left(\mathrm{Ser}^{239}\right)$, which is similar that natriuretic peptides weakly induce cGMP-dependent phosphorylation of VASP ( $\operatorname{Ser}^{239}$ ) (Borgogone et al., 2013), and PKA plays predominately to inhibit platelet aggregation ( $\mathrm{Li}$ et al., 2003).
Phosphorylated VASP is known to inhibit fibrinogen binding to $\alpha \mathrm{IIb} / \beta_{3}$ complex, which are concerned with inhibition of platelet activation (Horstrup et al., 1994; Barragan et al., 2003). Therefore, we examined whether the phosphorylation of VASP by cordycepin are associated with inhibition of fibrinogen binding to $\alpha \mathrm{IIb} / \beta_{3}$. As shown in Fig. 6 , collagen activated fibrinogen binding to $\alpha \mathrm{Ilb} / \beta_{3}$ (Fig. 6A-b) compared with intact cell, basal (Fig. 6A-a), and increased fibrinogen binding to $\alpha \mathrm{IIb} / \beta_{3}$ by $83.2 \pm 7.3 \%$ as compared with intact platelets, basal (Fig. 6B). However, cordycepin inhibited collagen-activated fibrinogen binding to $\alpha \mathrm{IIb} / \beta_{3}$ 
A
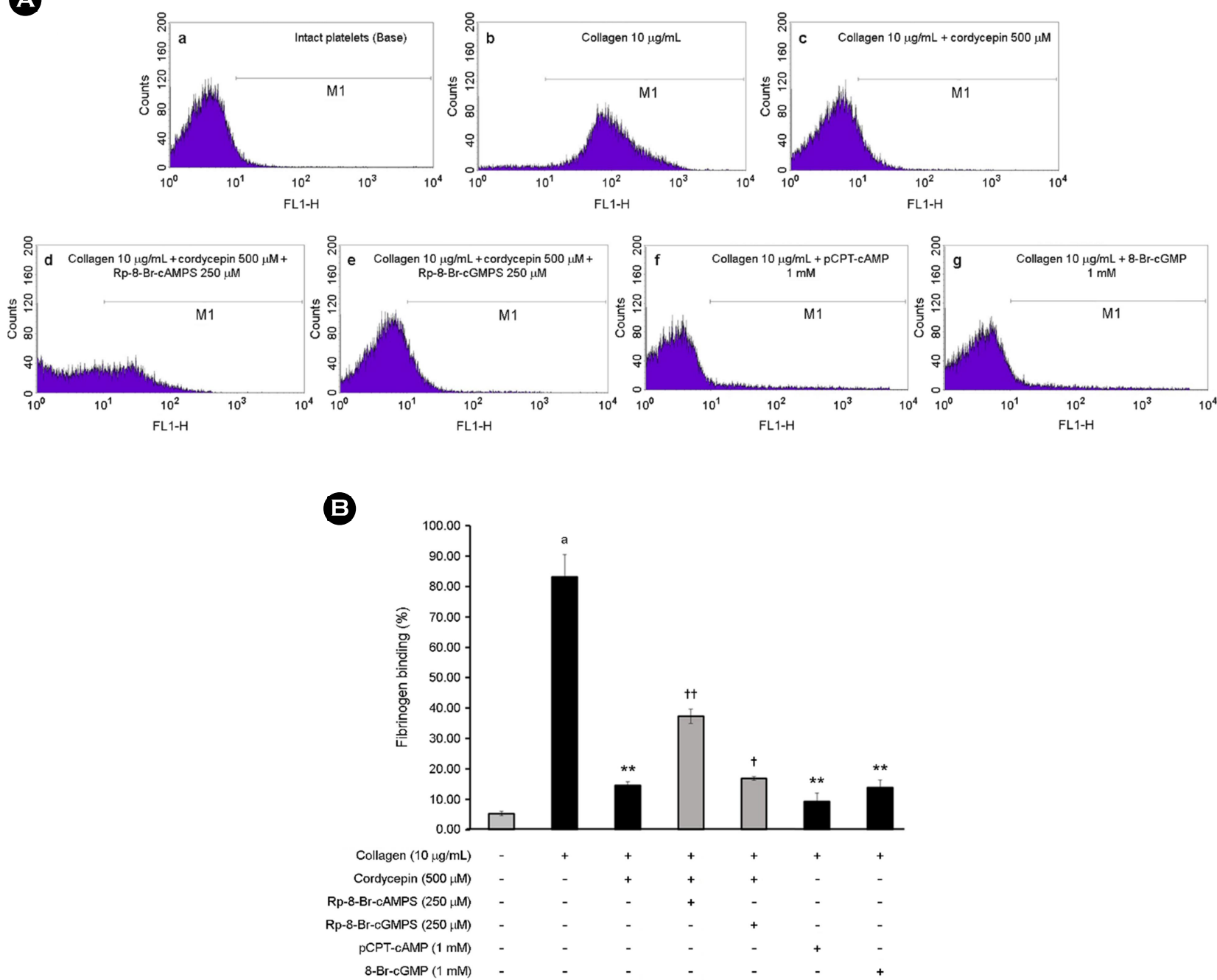

Fig. 6. Effect of cordycepin on fibrinogen binding. (A) The flow cytometry histograms on collagen-induced fibrinogen binding. a, Intact platelets; b, Collagen $(10 \mu \mathrm{g} / \mathrm{mL}) ; \mathrm{c}$, Collagen $(10 \mu \mathrm{g} / \mathrm{mL})+$ cordycepin $(500 \mu \mathrm{M}) ; \mathrm{d}$, Collagen $(10 \mu \mathrm{g} / \mathrm{mL})+$ cordycepin $(500 \mu \mathrm{M})+$ Rp-8-Br-cAMPS $(250 \mu \mathrm{M})$; e, Collagen $(10 \mu \mathrm{g} / \mathrm{mL})+$ cordycepin $(500 \mu \mathrm{M})+\mathrm{Rp}-8$-Br-cGMPS $(250 \mu \mathrm{M})$; f, Collagen $(10 \mu \mathrm{g} / \mathrm{mL})+\mathrm{pCPT}-$ cAMP $(1 \mathrm{mM})$; g, Collagen $(10 \mu \mathrm{g} / \mathrm{mL})+8$-Br-cGMP $(1 \mathrm{mM})$. (B) Effect of cordycepin on collagen-induced fibrinogen binding $(\%)$. The reactions were determined as described in "Methods". These data were expressed as the mean \pm SEM $(\mathrm{n}=4)$, and ${ }^{\mathrm{a}} P<0.05$ compared with non-stimulated platelets, ${ }^{* *} P<0.001$ compared with the collagen-stimulated platelets, ${ }^{\dagger} P<0.05,{ }^{\dagger} P<0.001$ compared with the collagenstimulated platelets in the presence of $500 \mu \mathrm{M}$ cordycepin.

by $14.5 \pm 1.2 \%$ (Fig. $6 \mathrm{~B}$ ). The inhibition of $\alpha \mathrm{IIb} / \beta_{3}$ is resulted from cAMP/PKA- or cGMP/PKG-mediated VASP phosphorylation, and it is known that cAMP- or cGMPincreasing compounds is associated with inhibition of $\alpha \mathrm{IIb} / \beta_{3}$ (Horstrup et al., 1994; Hauser et al., 1999; Barragan et al., 2003), so that we examined whether the inhibition of fibrinogen binding to $\alpha \mathrm{IIb} / \beta_{3}$ by cordycepin was contributed to cyclic-nucleotide of cAMP or cGMP. PKA activator pCPT-
cAMP or PKG activator 8-Br-cGMP inhibited collagenstimulated fibrinogen binding to $\alpha \mathrm{IIb} / \beta_{3}$ (Fig. 6A-f, g). It was confirmed that cAMP/PKA and cGMP/PKG pathway involve the inhibition of fibrinogen binding to $\alpha \mathrm{Ilb} / \beta_{3}$ in collagen-induced platelet activation. Cordycepin-inhibited fibrinogen binding to $\alpha \mathrm{Ilb} / \beta_{3}$ (Fig. 6A-c) was elevated by PKA inhibitor Rp-8-Br-cAMPS (Fig. 6A-d). However, cordycepin-inhibited fibrinogen binding to $\alpha \mathrm{IIb} / \beta_{3}$ was very 
slightly elevated by PKG inhibitor Rp-8-Br-cGMPS than Rp-8-Br-cAMPS (Fig. 6A-e). These results are in accord with that the inhibition of p-VASP (Ser ${ }^{157}$ ) by Rp-8-Br-cAMPS was stronger than Rp-8-Br-cGMPS (Fig. 5). Therefore, it is inferred that cordycepin-mediated $\alpha \mathrm{Ilb} / \beta_{3}$ inhibition was resulted from cAMP dependent-VASP $\left(\mathrm{Ser}^{157}\right.$ ) phosphorylation.

In conclusion, cordycepin contributed to cAMP-dependent phosphorylation of $\mathrm{IP}_{3} \mathrm{RI}\left(\mathrm{Ser}^{1756}\right)$ and VASP $\left(\mathrm{Ser}^{157}\right)$ to inhibit both $\left[\mathrm{Ca}^{2+}\right]_{i}$ mobilization and fibrinogen binding to $\alpha \mathrm{IIb} / \beta_{3}$, which accompanied the inhibition of platelet activation. Antiplatelet agents such as thienopyridine derivatives (i.e. clopidogrel, ticlopidine) have characteristics that inhibit $\left[\mathrm{Ca}^{2+}\right]_{\mathrm{i}}$ mobilization, phosphorylate VASP and inhibit $\alpha \mathrm{IIb} / \beta_{3}$ activation, which is mediated by cAMP- or cGMP-dependent manner (Barragan et al., 2003). Therefore, we suggest that cordycepin might represent a useful agent in prevention and therapy of vascular diseases (i.e., thrombosis, myocardial infarction, atherosclerosis, and ischemic cerebrovascular disease) associated with platelet activation.

\section{ACKNOWLEDGEMENTS}

This Research was supported by the Korea Nazarene University Research Grants 2017, and the author thanks professor Hwa-Jin Park for his sincere advice.

\section{CONFLICT OF INTEREST}

The author declares no conflict of interest.

\section{REFERENCES}

Barragan P, Bouvier JL, Roquebert PO, Macaluso G, Commeau P, Comet B, Lafont A, Camoin L, Walter U, Eigenthaler M. Resistance to thienopyridines: clinical detection of coronary stent thrombosis by monitoring of vasodilator-stimulated phosphoprotein phosphorylation. Catheterization and Cardiovascular Interventions. 2003. 59: 295-302.

Borgognone A, Lowe KL, Watson SP, Madhani M. Natriuretic peptides induce weak VASP phosphorylation at Serine 239 in platelets. Platelets. 2014. 25: 1-7.

Butt E, Abel K, Krieger M, Palm, D, Hoppe V, Hoppe J, Walter U. cAMP- and cGMP-dependent protein kinase phosphorylation sites of the focal adhesion vasodilator stimulated phospho- protein (VASP) in vitro and in intact human platelets. Journal of Biological Chemistry. 1994. 269: 14509-14517.

Cho HJ, Cho JY, Rhee MH, Park HJ. Cordycepin (3'-deoxyadenosine) inhibits human platelet aggregation in a cyclic AMP- and cyclic GMP-dependent manner. European Journal of Pharmacology. 2007. 558: 43-51.

Eigenthaler M, Nolte C, Halbrügge M, Walter U. Concentration and regulation of cyclic nucleotides, cyclic-nucleotidedependent protein kinases and one of their major substrates in human platelets. Estimating the rate of cAMP-regulated and cGMP-regulated protein phosphorylation in intact cells. European Journal of Biochemistry. 1992. 205: 471-481.

Gambaryan S, Kobsar A, Rukoyatkina N, Herterich S, Geiger J, Smolenski A, Lohmann SM, Walter U. Thrombin and collagen induce a feedback inhibitory signaling pathway in platelets involving dissociation of the catalytic subunit of protein kinase A from an NFkappaB-IkappaB complex. Journal of Biological Chemistry. 2010. 285: 18352-18363.

Halbrügge M, Walter U. Purification of a vasodilator-regulated phosphoprotein from human platelets. European Journal of Biochemistry. 1989. 185: 41-50.

Halbrügge M, Friedrich C, Eigenthaler M, Schanzenbächer P, Walter U. Stoichiometric and reversible phosphorylation of a 46-kDa protein in human platelets in response to cGMP- and cAMP-elevating vasodilators. Journal of Biological Chemistry. 1990. 265: 3088-3093.

Hauser W, Knobeloch KP, Eigenthaler M, Gambaryan S, Krenn V, Geiger J, Glazova M, Rohde E, Horak I, Walter U, Zimmer M. Megakaryocyte hyperplasia and enhanced agonist-induced platelet activation in vasodilator-stimulated phosphoprotein knockout mice. Proceedings of the National Academy of Sciences U.S.A. 1999. 96: 8120-8125.

Horstrup K, Jablonka B, Hönig-Liedl P, Just M, Kochsiek K, Walter U. Phosphorylation of focal adhesion vasodilatorstimulated phosphoprotein at $\mathrm{Ser}^{157}$ in intact human platelets correlates with fibrinogen receptor inhibition. European Journal of Biochemistry. 1994. 225: 21-27.

Johnston-Cox HA, Ravid K. Adenosine and blood platelets. Purinergic Signalling. 2011. 7: 357-365.

Kaibuchi K, Sano K, Hoshijima M, Takai Y, Nishizuka Y. Phosphatidylinositol turnover in platelet activation; calcium mobilization and protein phosphorylation. Cell Calcium. 1982. 3: 323-335.

Laurent V, Loisel TP, Harbeck B, Wehman A, Gröbe L, Jockusch BM, Wehland J, Gertler FB, Carlier MF. Role of proteins of 
the Ena/VASP family in actin-based motility of Listeria monocytogenes. Journal of Biological Chemistry. 1999. 144: 1245-1258.

Li Z, Ajdic J, Eigenthaler M, Du X. A predominant role for cAMP-dependent protein kinase in the cGMP-induced phosphorylation of vasodilator-stimulated phosphoprotein and platelet inhibition in humans. Blood. 2003. 101: 4423-4429.

Nieswandt B, Bergmeier W, Eckly A, Schulte V, Ohlmann P, Cazenave JP, Zirngibl H, Offermanns S, Gachet C. Evidence for cross-talk between glycoprotein $\mathrm{VI}$ and $\mathrm{G}_{\mathrm{i}}$-coupled receptors during collagen-induced platelet aggregation. Blood. 2001. 97: 3829-3835.

Nishikawa M, Tanaka T, Hidaka H. $\mathrm{Ca}^{2+}$-calmodulin dependent phosphorylation and platelet secretion. Nature. 1980. 287: 863 -865 .

Pasqui AL, Capecchi PL, Ceccatelli L, Mazza S, Gistri A, Laghi Pasini F, Di Perri T. Nitroprusside in vitro inhibits platelet aggregation and intracellular calcium translocation. Effect of haemoglobin. Thrombosis Research. 1991. 61: 113-122.

Quinton TM, Dean WL. Cyclic AMP-dependent phosphorylation of the inositol-1,4,5-trisphosphate receptor inhibits $\mathrm{Ca}^{2+}$ release from platelet membranes. Biochemical and Biophysical Research Communications. 1992. 184: 893-899.

Schaeffer J, Blaustein MP. Platelet free calcium concentrations measured with fura-2 are influenced by the transmembrane sodium gradient. Cell Calcium. 1989. 10: 101-113.

Schwartz SM, Heinmark RL, Majesky MW. Developmental mechanisms underlying pathology of arteries. Physiological Reviews.
1990. 70: $1177-1209$.

Schwarz UR, Walter U, Eigenthaler M. Taming platelets with cyclic nucleotides. Biochemical Pharmacology. 2001. 62: 1153-1161.

Smolenski A, Bachmann C, Reinhard K, Honig-Liedl P, Jarchau T, Hoschuetzky H, Walter U. Analysis and regulation of vasodilator-stimulated phosphoprotein serine 239 phosphorylation in vitro and in intact cells using a phosphospecific monoclonal antibody. Journal of Biological Chemistry. 1998. 273: 20029-20035.

Sudo T, Ito H, Kimura Y. Phosphorylation of the vasodilatorstimulated phosphoprotein (VASP) by the anti-platelet drug, cilostazol, in platelets. Platelets. 2003. 14: 381-390.

Walter U, Gambaryan S. cGMP and cGMP-dependent protein kinase in platelets and blood cells. Handbook of Experimental Pharmacology. 2009. 191: 533-548.

Wonerow P, Obergfell A, Wilde JI, Bobe R, Asazuma N, Brdicka T, Leo A, Schraven B, Horejsí V, Shattil SJ, Watson SP. Differential role of glycolipid-enriched membrane domains in glycoprotein VI- and integrin-mediated phospholipase Cgamma2 regulation in platelets. Biochemical Journal. 2002. 364: 755-765.

https://doi.org/10.15616/BSL.2017.23.3.251

Cite this article as: Lee DH. Inhibitory Effects of Cordycepin on Platelet Activation via Regulation of Cyclic Adenosine Monophosphate-downstream Pathway. Biomedical Science Letters. 2017. 23: 251-260. 